\title{
EDITORIAL
}

\section{A rose by any other name}

DOI: $10.5770 /$ cgj.v14i3.24

I am pleased to introduce the third online issue of the Canadian Geriatrics Journal. This issue has a number of papers on a range of topics including neuropsychology, telemedicine, and the history of a prominent Canadian geriatrics research prize.

Why is the Kaufman named the Kaufman? This is not a koan but the topic of a paper by Dr. Hogan (University of Calgary), who presents a historical review of the person behind the name of the Kaufman Prize, a prominent award given by the Canadian Geriatrics Society for approximately 30 years. This prize has served for many years to encourage excellence in gerontological research, but society members generally do not know the history of the individual the prize was named after. Dr. Hogan provides a useful review of the origins of the Kaufman Prize and the controversial past of its namesake.
Our other articles address less controversial issues currently important to geriatric medicine, such as barriers to assessing fitness to drive (Dr. Moorhouse, Dalhousie University), the use of telemedicine techniques in the older adult population (Dr. Larner, Walton Centre for Neurology and Neurosurgery), the effects of normal aging on processing speed and verbal fluency (Dr. Elgamal, University of Waterloo), and the use of psychotropic medications in Canadian long-term care patients (Dr. Fischer, University of Toronto). It is exciting to see the breadth of research encompassed by the term "geriatrics."

Have a great fall! Ken M. Madden, Editor-in-Chief 